\title{
GEMPA MENURUT AL QURAN DAN SISTEM STRUKTUR BANGUNAN
}

\author{
Agung Sedayu \\ Jurusan Teknik Arsitektur Universitas Islam Negeri Maulana Malik \\ Ibrahim Malang, Jalan Gajayana No. 50, Telp. 08155172619, email: agung_ \\ resta@yahoo.co.id
}

\begin{abstract}
Earthquake is very attractive to be studied from the perspective of al Quran and also from the perspective of building construction system. Earthquake is one of natural disasters which mentioned in al Quran. Earthquake is also classified as one of building construction's load. Earthquake can be caused by formations of earth coat which is not uniform, thus makes the coat moves from its position. The change of coat then caused a formation of earth itself and an uncontrolled exploitation of natural resources which forces the change in geological formation. One of important principles of civil building is to place human in the highest priority to be protected against all kinds of building's encumbrance. In planning a building's resistance to earthquake, a planning concept based on performance (performance based-design) is used by specifying several levels of structure performances (multiple performance levels). This performance grade is the level of building's performance which is expected will be done at the building structure to accept earthquake load with certain intensity level. This planning conception has become the newest trend nowadays, which represents a combination of the aspect of prisoners and the aspect of helpers. The characteristics of seismic structure are evaluated using the performance evaluation that consists of pushover analyses and inelastic dynamic time history analyses.
\end{abstract}

Gempa merupakan fenomena alam yang sangat menarik untuk dipelajari dari sudut pandang al Quran dan dari sudut pandang sistem konstruksi bangunan. Gempa merupakan salah satu bencana alam yang disebutkan di dalam al Quran. Dalam ilmu konstruksi bangunan, gempa merupakan salah satu jenis beban yang dapat mengenai bangunan. Gempa dapat disebabkan oleh pembentukan lapisan bumi yang tidak seragam, Hal ini menyebabkan lapisan

Ulul Albab Volume 11, No.1 Tahun 2010 
tersebut berusaha bergerak dan berpindah. Perubahan lapisan tersebut disebabkan oleh karena susunan lapisan bumi itu sendiri dan ulah serakah manusia dalam melakukan eksploitasi sumber daya alam yang memaksa terjadinya perubahan susunan dan perletakan lapisan tanah. Azas utama penyediaan bangunan sipil adalah untuk tujuan kemanusiaan. Hal tersebut mempunyai makna bahwa unsur hakikat manusia ditempatkan pada posisi tertinggi untuk dilindungi dari segala macam pembebanan bangunan. Metode yang akurat, valid dan lengkap dalam merencanakan ketahanan bangunan terhadap gempa, salah satunya adalah konsep perencanaan berbasis kinerja (performance based-design) dengan menetapkan berbagai tingkat kinerja struktur (multiple performance levels). Tingkat kinerja ini adalah tingkat kinerja bangunan yang diharapkan terjadi pada saat struktur menerima beban gempa dengan tingkat intensitas tertentu. Konsep perencanaan tersebut menjadi tren terbaru saat ini, dimana konsep ini merupakan kombinasi dari aspek tahanan dan aspek layan. Perilaku-perilaku seismik struktur dievaluasi dengan menggunakan evaluasi kinerja dengan menggunakan analisis beban dorong (pushover) dan analisis inelastik dinamik riwayat waktu (inelastic dynamic time history).

Key words: al Quran, structural system, earthquake

\section{Pendahuluan}

"Karena itu mereka ditimpa gempa maka jadilah mereka mayat-mayat yang bergelimpangan di tempat tinggal mereka" (QS al Raaf: 78). Sejak dua puluh tahun terakhir Indonesia mendapatkan musibah gempa yang berurutan dengan skala kuantitas relatif besar. Secara geologi Indonesia merupakan negara yang terletak diantara pertemuan patahan lempeng bumi. Indonesia termasuk wilayah rawan gempa, dimulai sejak tahun 1992 yang terjadi di Flores yang memakan korban lebih dari 4.000 jiwa manusia, dan dua belas tahun kemudian pada tahun 2004 terjadi gempa Aceh yang disertai juga dengan tsunami yang memakan korban jiwa ratusan ribu nyawa. Korban manusia akibat gempa Aceh 26 Desember 2004 lebih dari 180.000 orang, akibat gempa Nias 15 Maret 2005 lebih dari 3.000 orang sementara korban akibat gempa Yogyakarta 27 Mei 2006 lebih dari 5.700 orang (Widodo, 2007: 2). Selain itu juga terjadi gempa-gempa berikutnya yakni gempa Padang, Banten, Bima, Tasikmalaya, dan gempa Papua. Gempa sangat menarik untuk dikaji baik dalam perspektif al Quran maupun sistem konstruksi bangunan. Gempa sebagai fenomena alam yang dikatakan sebagai bencana banyak disebutkan di dalam al Quran, dan gempa itu sendiri merupakan beban dahsyat yang dapat meruntuhkan bangunan. Gempa dapat disebabkan oleh aktivitas gunung berapi (Vulkanik), runtuhan benda angkasa yang jatuh ke bumi 
(Meteor), dan pergerakan lempeng batuan bumi (Tektonik). Diantara ketiga jenis gempa tersebut gempa tektonik-lah yang paling dahsyat dan seringkali terjadi, serta datangnya gempa tersebut sulit diprediksi, bahkan dampaknya dapat menyebabkan gelombang Tsunami yang menambah korban jiwa seperti yang terjadi di Aceh enam tahun lalu.

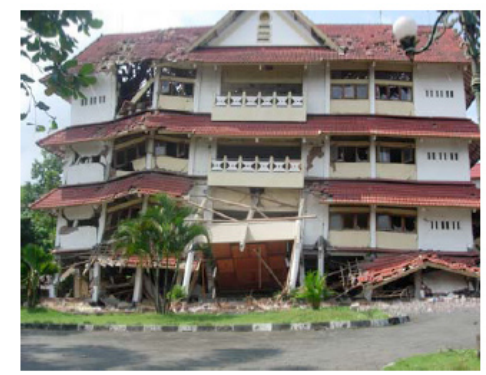

Gambar 1.

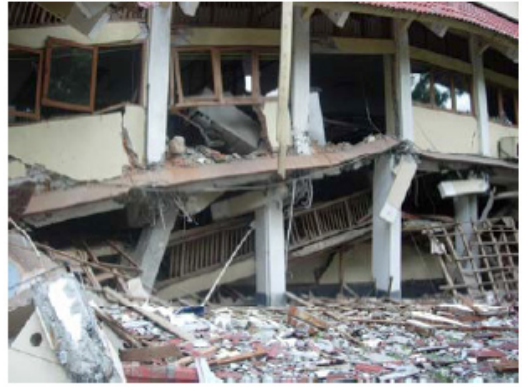

Gambar 2.

Gambar 1. Bagian Depan Kerusakan Bangunan STIE Yogyakarta sebab gempa 2006 (Sumber: Widodo, 2007: 11). Gambar 2. Bagian Dalam Kerusakan Bangunan STIE Yogyakarta sebab gempa 2006 (Sumber: Widodo, 2007: 11)

\section{Gempa di dalam Al Quran}

Berbicara masalah gempa maka tidak terlepas dengan pembahasan mengenai bumi atau tanah. Langit dan bumi banyak disebutkan bersamaan di dalam al Quran, hal ini tentu ada hikmah khusus yang disampaikan Allah SWT. kepada manusia, sebagaimana firman-Nya: "Dan tidaklah Kami ciptakan Iangit dan bumi dan segala yang ada diantara keduanya dengan bermain-main" (QS al Anbiya: 16).

Maksudnya Allah SWT. menciptakan langit dan bumi dan apa yang ada diantara keduanya itu adalah dengan maksud dan tujuan yang mengandung hikmah, agar manusia selalu bersyukur dan memahami serta mengakui keesaan dan kemahaperkasaan Allah aza wajalla. Gempa bumi dapat disebabkan oleh susunan lapisan bumi yang tidak seragam, hal ini menyebabkan lapisan tersebut berusaha bergerak dan berpindah. Perubahan lapisan tersebut disebabkan oleh karena susunan lapisan bumi itu sendiri dan ulah serakah manusia dalam melakukan eksploitasi sumber daya alam baik minyak bumi, gas alam, bahan tambang lain yang memaksa susunan lapisan tanah menjadi berubah susunan atau letaknya, kasus ini dinamakan lapisan tanah mengalami disposisi atau settlement. Gempa yang terjadi akhir-akhir banyak yang menyebut sebagai bencana atau musibah bagi manusia, padahal kalau diteliti penyebabnya gempa 
bukanlah dikategorikan bencana alam murni karena gejala alam, namun diperkirakan disebabkan oleh ulah tangan manusia sendiri, seperti yang kita ketahui bahwa banyak ekploitasi hasil bumi baik dalam lapisan bumi maupun di atas permukaan bumi. Ada beberapa firman Allah SWT yang menyebutkan tentang gempa, bahkan sejarah manusia lampau yang mengalami musibah gempa juga diceritakan.

\section{Firman Allah SWT,}

"Apakah kamu merasa aman terhadap Allah yang (berkuasa) di langit bahwa Dia akan menjungkir balikkan bumi bersama kamu, sehingga dengan tiba-tiba bumi itu bergoncang?" (QS al Mulk: 16).

\section{Firman Allah SWT,}

"Maka Kami benamkanlah Karun beserta rumahnya ke dalam bumi. Maka tidak ada baginya suatu golongan pun yang menolongnya terhadap azab Allah. Dan tiadalah ia termasuk orang-orang (yang dapat) membela (dirinya)" (al Qashash: 81).

\section{Firman Allah SWT,}

Dan Musa memilih tujuh puluh orang dari kaumnya untuk (memohonkan taubat kepada Kami) pada waktu yang telah Kami tentukan. Maka ketika mereka digoncang gempa bumi, Musa berkata: "Ya Tuhanku, kalau Engkau kehendaki, tentulah Engkau membinasakan mereka dan aku sebelum ini. Apakah Engkau membinasakan kami karena perbuatan orang-orang yang kurang akal diantara kami? Itu hanyalah cobaan dari Engkau, Engkau sesatkan dengan cobaan itu siapa yang Engkau kehendaki dan Engkau beri petunjuk kepada siapa yang Engkau kehendaki. Engkaulah Yang memimpin kami, maka ampunilah kami dan berilah kami rahmat dan Engkaulah Pemberi ampun yang sebaik-baiknya" (QS al A'raaf: 155).

\section{Firman Allah SWT,}

"Apabila bumi digoncangkan dengan goncangan (yang dahsyat), dan bumi telah mengeluarkan beban-beban berat (yang dikandung) nya, dan manusia bertanya: "Mengapa bumi (menjadi begini)?" (QS al Zalzalah: 1 - 3).

Dari empat ayat di atas bahwa Allah SWT akan memberikan azab atau hukuman bagi manusia yang telah lalai akan risalah melalui Rasul-Nya yang telah disampaikan pada kaumnya di waktu itu. Memaknai gempa sebagai gejala alam biasa, azab, ujian atau cobaan bergantung pada cara pandang dan introspeksi diri masing-masing manusia. Gempa sebagai azab yang diturunkan oleh Allah 
SWT, disebabkan ulah manusia yang telah melampaui batas dan merajalela dengan tidak mematuhi dan mengindahkan perintah yang disyariatkan oleh Allah SWT. Allah SWT menciptakan segala sesuatu dengan sempurna dan seimbang, hanya manusialah yang merusak dan mengganggu keseimbangan tersebut, sebagaimana firman-Nya,

"Yang kepunyaanNya-lah kerajaan langit dan bumi, dan Dia tidak mempunyai anak, dan tidak ada sekutu bagi-Nya dalam kekuasaan-Nya), dan dia telah menciptakan segala sesuatu, dan Dia menetapkan ukuran-ukurannya dengan serapi-rapinya"(QS al Furqon: 2).

Di ayat yang lain Allah SWT telah banyak memberikan peringatan keras bagi manusia agar bertindak tidak merugikan atau merusak orang lain dan lingkungan. Kecenderungan manusia selalu lupa dan melampaui batas, maka Allah SWT memberi peringatan sebagaimana firman-Nya,

"Sesungguhnya dosa itu atas orang-orang yang berbuat zalim kepada manusia dan melampaui batas di muka bumi tanpa hak. Mereka itu mendapat azab yang pedih" (QS asy Syuura: 42).

\section{Firman Allah SWT,}

"Maka masing-masing (mereka itu) Kami siksa disebabkan dosanya, maka diantara mereka ada yang Kami timpakan kepadanya hujan batu kerikil dan diantara mereka ada yang ditimpa suara keras yang mengguntur, dan diantara mereka ada yang Kami benamkan ke dalam bumi, dan diantara mereka ada yang Kami tenggelamkan, dan Allah sekali-kali tidak hendak menganiaya mereka, akan tetapi merekalah yang menganiaya diri mereka sendiri (QS al 'Ankabuut: 40).

\section{Firman Allah SWT,}

"Dan janganlah kamu merugikan manusia pada hak-haknya dan janganlah kamu merajalela di muka bumi dengan membuat kerusakan; (QS asy Syu'araa': 183).

\section{Firman Allah SWT,}

Maka mengapa tidak ada dari umat-umat yang sebelum kamu orangorang yang mempunyai keutamaan yang melarang daripada (mengerjakan) kerusakan di muka bumi, kecuali sebahagian kecil diantara orang-orang yang telah Kami selamatkan diantara mereka, dan orang-orang yang zalim hanya mementingkan kenikmatan yang mewah yang ada pada mereka, dan mereka adalah orang-orang yang berdosa (QS Huud: 116). 
Dari empat ayat di atas menjelaskan bahwa Allah SWT sangat tidak menyukai manusia yang bertindak merusak lingkungan, merugikan orang lain, berlaku zalim, dan mementingkan kenikmatan duniawi yang mewah. Dan Allah SWT melihat kondisi kaum seperti itu menurunkan azab-Nya karena telah melampaui batas.

\section{Kesetimbangan dan Kestabilan Struktur Bangunan}

Gaya meliputi gaya lintang dan gaya normal, di mana gaya lintang adalah gaya yang berarah tegak lurus atau memotong penampang, sedangkan gaya normal merupakan gaya yang menimpa penampang searah garis sumbu penampang. Pengaruh beban lain pada balok adalah momen, di mana kecenderungan dari sebuah gaya untuk berputar terhadap suatu titik. Reaksireaksi yang terjadi bergantung pada jenis perletakan atau tumpuan struktur yang lain misalnya pertemuan balok-kolom, balok-plat lantai, dan lain-lain. Perletakan atau tumpuan yang berbeda akan menyebabkan momen yang berbeda pula. Selain pengaruh beban dan momen, turut diperhatikan pula adalah karakter bahan struktur tersebut, baik jenis, dimensi, dan kekuatan bahan. Beban-beban mengenai struktur dalam bentuk beban terpusat maupun beban merata dengan kombinasi beban yang beragam. Dalam hukum kesetimbangan struktur bangunan dicapai apabila Aksi = Reaksi (Vis dan Kusuma, 1993: 19). Untuk 'struktur statis tertentu' hal ini berlaku jika berlaku tiga persyaratan persamaan keseimbangan pada berbagai komponen (bagian-bagian struktur) yaitu: jumlah, momen, jumlah gaya-gaya horizontal, dan vertikal yang bekerja pada struktur sama dengan nol. Diringkas sebagai berikut $\Sigma \mathrm{M}=0, \Sigma \mathrm{H}=0$, $\Sigma \mathrm{V}=0$.

\section{Gempa Bumi sebagai Beban Dinamis Bangunan}

Ditinjau dari perspektif Teknik Sipil Struktur, gempa bumi merupakan fenomena alam yang sangat menarik untuk dibahas. Hal itu disebabkan karena begitu besar korban manusia dan harta benda yang telah terjadi (Widodo, 2007: 3). Azas utama penyediaan bangunan sipil adalah untuk tujuan kemanusiaan. Hal tersebut mempunyai makna bahwa unsur hakikat manusia ditempatkan pada posisi tertinggi untuk dilindungi dari segala macam pembebanan bangunan. Manusia sebagai penghuni bangunan harus dapat tinggal secara aman, nyaman, dan terjangkau pembangunannya. Oleh karena itu para ahli, para peneliti, maupun para praktisi harus dan telah menunjukkan dedikasinya, 
telah bekerja sangat keras guna memenuhi kebutuhan bangunan tersebut, sebagai suatu sumbangan terhadap kemanusiaan (Widodo, 2007: 12).

Civil engineers dan Arsitek, mempunyai tanggung jawab moral yang besar untuk tujuan dan maksud tersebut. Dengan demikian adalah sangat naif bagi civil engineers dan arsitek yang hanya menempatkan perolehan finansial terhadap jasa bangunan yang disediakan sementara kualitas ataupun keamanan bangunan terkesampingkan. Hal di atas tidak hanya tanggung jawab namun juga merupakan amanah yang ada pertanggungjawaban di hadapan Allah SWT, sebagaimana firman-Nya,

"Sesungguhnya Allah menyuruh kamu menyampaikan amanat kepada yang berhak menerimanya, dan (menyuruh kamu) apabila menetapkan hukum diantara manusia supaya kamu menetapkan dengan adil. Sesungguhnya Allah memberi pengajaran yang sebaik-baiknya kepadamu. Sesungguhnya Allah maha Mendengar lagi Maha Melihat" (QS an Nisaa': 58).

Rasulullah bersabda: "Bahwa amanah akan menarik rezeki dan sebaliknya khianat akan mengakibatkan kefakiran” (ad Dailami).

Indonesia berdasarkan tinjauan geologis memang terletak diantara patahan lempeng batuan bumi. Hal ini akan menyebabkan pergerakan tanah yang tidak dapat diperkirakan intensitas, waktu, dan kuantitasnya. Kerugian jiwa yang diakibatkan oleh gempa sebagian besar disebabkan oleh rusak atau runtuhnya bangunan berupa tempat tinggal, kantor, hotel, rumah sakit, mal dan lain-lain yang di dalamnya dihuni oleh manusia. Terlepas dari kejadian gempa adalah kehendak Allah SWT, namun korban manusia bukanlah akibat langsung dari kejadian gempa itu sendiri, tetapi lebih banyak akibat keruntuhan bangunan buatan manusia, buatan praktisi, buatan civil engineers dan arsitek. Gempa bumi hadir pada bangunan sebagai beban yang sangat dinamis, hampir semua standard dan peraturan sistem struktur bangunan di semua Negara memasukkan gempa dalam kombinasi pembebanannya. Salah satunya adalah menurut SK SNI T-15-1991-03 tentang Tata Cara Perhitungan Struktur Beton Untuk Bangunan bahwa kombinasi pembebanan untuk kuat perlu (U) akibat beban gempa adalah:

$$
\begin{aligned}
& \mathrm{U}=1,05\left(\mathrm{D}+\mathrm{L}_{\mathrm{R}} \pm \mathrm{E}\right) \\
& \text { atau } \\
& \mathrm{U}=0,9(\mathrm{D} \pm \mathrm{E})
\end{aligned}
$$


Dengan: $U=$ Kuat perlu

$\mathrm{D}=$ Beban Mati

$\mathrm{L}_{\mathrm{R}}=$ Beban hidup yang telah direduksi menurut SNI 1726 - 2003 tentang Tata

Cara Perencanaan Ketahanan Gempa Untuk Rumah dan Gedung $\mathrm{E}=$ Beban gempa menurut SNI 1726-2003

Dalam filosofi perencanaan struktur beton di daerah gempa dikenal suatu konsep pembebanan 2 tingkat yakni struktur beton selama masa layannya akan dibebani berkali-kali oleh gempa-gempa kecil sampai sedang yang mempunyai waktu ulang 20-50 tahun. Sedangkan gempa besar waktu ulangnya terjadi sekali selama 200 tahun (Vis dan Kusuma, 1993: 238). Besarnya beban gempa ini tergantung dari waktu getar struktur beban tersebut.

Besarnya gaya gempa ini dinyatakan dalam:

$$
\mathrm{V}=\mathrm{C} I \mathrm{~K} \mathrm{Wt}
$$

Dengan

$\mathrm{V}=$ Beban geser dasar akibat gempa

$\mathrm{C}=$ Koefisien gempa dasar

I $=$ Faktor keutamaan

$\mathrm{k}=$ Faktor jenis struktur

$\mathrm{Wt}_{\mathrm{t}}=$ Kombinasi dari beban mati seluruhnya dan beban hidup vertikal

$\mathrm{T}=$ Waktu getar alami struktur gedung

Harga C dapat dicari dari diagram respon spectrum dengan mengetahui waktu getar $\mathrm{T}$ struktur tersebut. Respon spectra $20^{\text {th }}$ untuk tiap zone dibagi faktor $\mathrm{f}_{1}$ dan $\mathrm{f}_{2}$ dengan $\mathrm{f}_{2}$ adalah faktor kelebihan kekuatan struktur statis tak tentu dalam keadaan plastis. Sedangkan $\mathrm{f}_{1}$ adalah faktor kelebihan kekuatan struktur akibat kelebihan kekuatan pada penampang beton terutama pada penulangannya (Vis dan Kusuma, 1993: 38).

$\mathrm{f}_{1}=1,5$
$\mathrm{f}_{2}=2$

$C$ peraturan $=\frac{C_{\mathrm{D} \text { th }}}{f_{1} \cdot f_{2}}$

Agar struktur beton tetap direncanakan dengan beban gempa 200 
tahunan. Maka struktur beton harus mempunyai nilai daktilitas yang cukup besar $(\mu)$ dengan

$$
C \text { peraturan }>\frac{C_{200 \text { th }}}{f_{1} \cdot \mathrm{m}}
$$

Bila struktur beton tidak memiliki daktilitas yang cukup maka perencanaan struktur dapat dilakukan dengan meningkatkan nilai K (faktor daktilitas struktur).

\section{Konsep Perencanaan Bangunan Tahan Gempa Berbasis Kinerja}

Firman Allah SWT: "Sesungguhnya Allah menyukai orang yang berperang dijalan-Nya dalam barisan yang teratur seakan-akan mereka seperti suatu bangunan yang tersusun kokoh" (QS ash Shaff: 4).

Negara Indonesia dalam merencanakan ketahanan struktur bangunannya terhadap beban gempa masih banyak menggunakan konsep perhitungan berbasis gaya (strength based). Untuk Negara-negara yang sudah maju sudah menggunakan metode yang lebih akurat, valid dan lengkap dalam merencanakan ketahanan bangunan terhadap gempa, konsep tersebut adalah perencanaan berbasis kinerja (Performance Based-Design) dengan menetapkan berbagai tingkat kinerja struktur (multiple performance levels). Tingkat kinerja ini adalah tingkat kinerja bangunan yang diharapkan terjadi pada saat struktur menerima beban gempa dengan tingkat intensitas tertentu (Lumantarna, 2008: 1). Kinerja struktur yang diharapkan ditunjukkan pada Gambar 3 di bawah ini.

\section{Earthquake Performance Level}

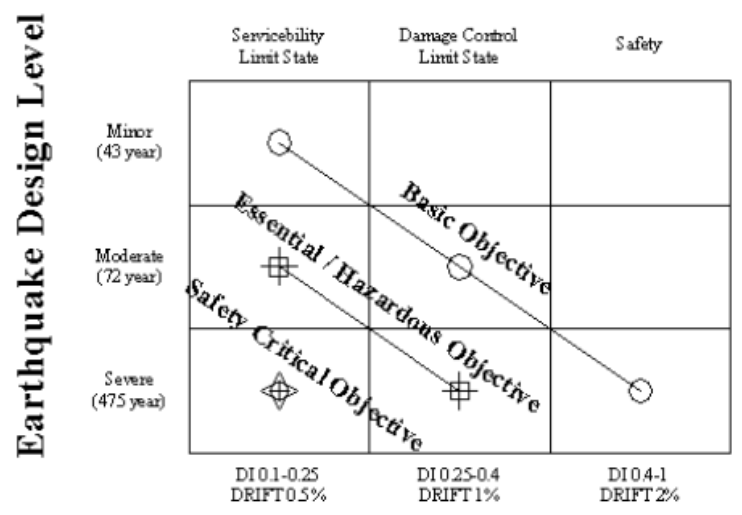

Gambar 3. Tingkatan dan Sasaran Kinerja Struktur Bangunan 
(Sumber: Asian Concrete Model Code (ACMC), 1999: 78)

Konsep perencanaan tersebut menjadi trend terbaru saat ini, dimana konsep ini merupakan kombinasi dari aspek tahanan dan aspek layan (Pranata, 2006: 43). Perilaku-perilaku seismik struktur dievaluasi dengan menggunakan evaluasi kinerja dengan menggunakan analisis beban dorong (Pushover) dan analisis inelastik dinamik riwayat waktu (Inelastic Dynamic Time History).

\section{Analisis Beban Dorong (Pushover)}

Analisis beban dorong adalah suatu analisis statik nonlinier dimana pengaruh gempa rencana terhadap struktur bangunan gedung dianggap sebagai beban-beban statik yang menangkap pada pusat massa masing-masing elemen lantai, yang nilainya ditingkatkan secara berangsur-angsur sampai melampaui pembebanan yang menyebabkan terjadinya pelelehan (sendi plastis) pertama di dalam struktur bangunan gedung, kemudian dengan peningkatan beban lebih lanjut mengalami perubahan bentuk pasca-elastik yang besar sampai mencapai kondisi plastik. Contoh perilaku-perilaku seismik struktur bangunan gedung ditunjukkan Gambar 4.

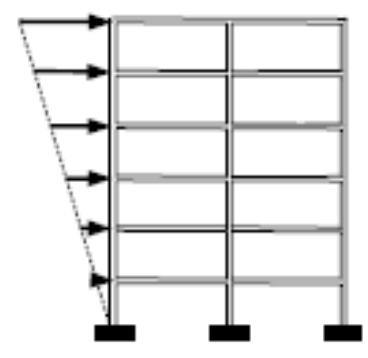

4(a)

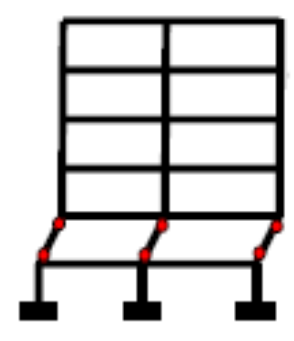

$4(\mathrm{~b})$

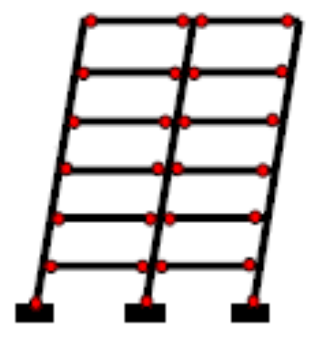

4(c)

Gambar 4. a. Distribusi gaya geser pada bangunan. 4. b. Perilaku sendi plastis lokal bangunan karena beban geser gempa. 4. c. Perilaku sendi plastis menyeluruh bangunan karena beban geser gempa (Sumber: Widodo, 2007: 5).

Salah satu contoh perilaku seismik bangunan karena beban geser gempa adalah ditunjukkan pada Gambar 5 di bawah, dimana gempa terjadi pada bangunan bermassa dengan dilatasi antar massa bangunan akan menyebabkan benturan. 


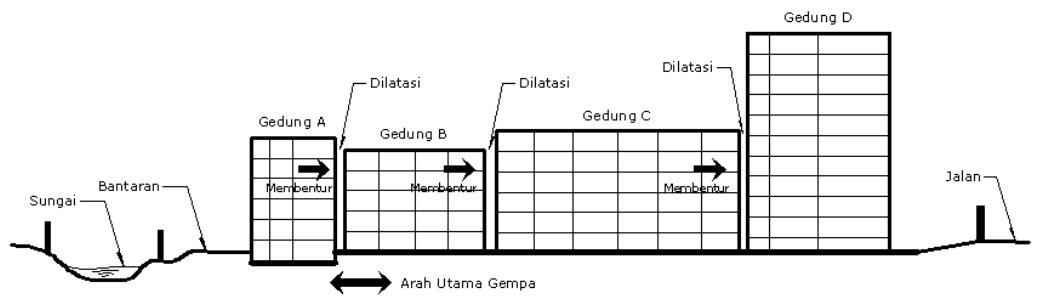

Gambar 5. Contoh pembebanan gempa pada struktur bangunan (Sumber: Widodo, 2007: 8)

\section{Analisis Inelastik Dinamik Riwayat Waktu (Inelastic Dynamic Time History)}

\section{Firman Allah SWT,}

"Demi masa, sesungguhnya manusia itu benar-benar dalam kerugian, kecuali orang-orang yang beriman dan mengerjakan amal saleh dan nasehat menasehati supaya mentaati kebenaran dan nasehat menasehati supaya menetapi kesabaran" (QS al 'Ashr 1 - 3).

\section{Firman Allah SWT,}

"Dan (penduduk) negeri telah Kami binasakan ketika mereka berbuat zalim, dan telah Kami tetapkan waktu tertentu bagi kebinasaan mereka" (QS al Kahfi: 59).

Beban gempa adalah fungsi waktu, sehingga respon pada struktur juga tergantung dari waktu pembebanan. Akibat gempa rencana struktur akan berperilaku inelastik (Pranata, 2006: 44). Untuk mendapatkan respon struktur tiap waktu dengan memperhitungkan perilaku nonlinier, maka dilakukan analisis riwayat waktu inelastik nonlinier dengan analisis langkahlangkah (metode integrasi bertahap). Input gempa yang dilakukan adalah dengan mengambil gempa yang pernah terjadi di Indonesia maupun negara lain. Contoh input riwayat gempa yang dapat dimasukkan untuk gempa di Indonesia adalah gempa Flores tahun 1992 dengan skala 6,8 SR. Gambar 6 di bawah menunjukkan akselerogram gempa Flores tahun 1992.

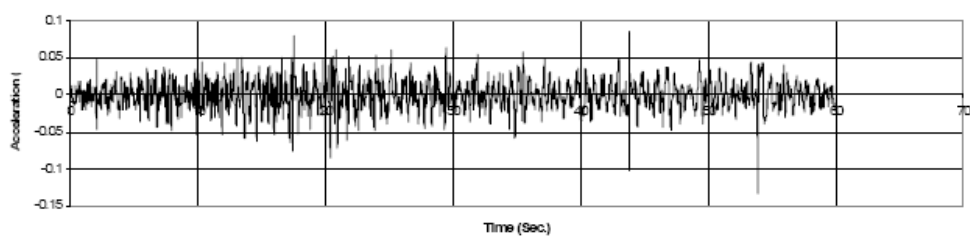

Gambar 6. Akselerogram gempa Flores 1992 (Sumber: Pranata, 2006: 45) 


\section{Gempa Menurut al Quran dan Sistem Struktur Bangunan}

\section{Simpulan}

Gempa merupakan fenomena alam yang berupa pergerakan atau getaran tanah dan lapisannya oleh sebab aktivitas gunung api, runtuhan benda angkasa, dan pergeseran lapisan batuan bumi. Gempa juga merupakan bentuk ujian, peringatan, maupun azab Allah SWT kepada manusia karena telah melampaui batas dalam melanggar larangan-Nya dan tidak mengindahkan perintah-Nya. Gempa dapat terjadi karena kesalahan manusia sendiri karena telah merusak dan mengganggu keseimbangan susunan dan lapisan tanah, sehingga tanah saling bergerak atau berpindah karena perubahan tersebut. Pergerakan atau perpindahan tanah yang disebut gempa ini menjadi beban statik maupun dinamik bagi struktur bangunan. Banyak korban jiwa akibat bangunan runtuh gaya geser oleh gempa. Perencanaan ketahanan bangunan gedung terhadap gempa dapat menggunakan pendekatan berbasis gaya (strength based) dan berbasis kinerja (performance based). Konsep perencanaan berbasis kinerja ini merupakan kombinasi dari aspek tahanan dan aspek layan. Perilaku-perilaku seismik struktur dievaluasi dengan menggunakan evaluasi kinerja dengan menggunakan analisis beban dorong (Pushover) dan analisis inelastik dinamik riwayat waktu (Inelastic Dynamic Time History).

\section{Daftar Pustaka}

ACMC. 1999. Asian Concrete Model Code, Level $1 \& 2$ Documenst, Second Draft. Japan: International Committee on Concrete Model Code.

Kusuma, Gideon. 1993. Pedoman Pengerjaan Beton Berdasarkan SKSNI T-15-1991-03. Jakarta: Erlangga.

Kusuma, Gideon. 1993. Desain Struktur Rangka Baton Bertulang di Daerah Rawan Gempa. Jakarta: Erlangga.

Lumantarna, Benjamin. 2008. Performance Based Design, Sebaiknya Menggunakan Modal Pushover Analysis atau Capacity Spectrum Method. Semarang: Seminar dan Pemeran HAKI 2008.

Pranata, Yosafat Aji. 2006. Jurnal Evaluasi Kinerja Gedung Beton Bertulang Tahan Gempa dengan Pushover Analysis (Sesuai ATC-40, FEMA 356, dan FEMA 440. Bandung: Jurusan Teknik Sipil Universitas Kristen Maranatha.

SNI 03-1726-2003. 2003. Tata Cara Perencanaan Bangunan Tahan Gempa. Departemen Permukiman dan Prasarana Wilayah. 
SKSNI 15-1991-03. 1991. Tata Cara Perhitungan Struktur Beton Bertulang. Departemen Pekerjaan Umum.

Widodo. 2007. Kerusakan Bangunan Pada Gempa Yogyakarta 27 Mei 2006: Akibat Kebelumjelasan Code, sosialisasi atau Peleksanaan. Yogyakarta: Seminar dan Pameran HAKI 2007. 